This article has been published in a revised form in Journal of Management \& Organization https://doi.org/10.1017/ jmo.2019.51. This version is free to view and download for private research and study only. Not for re-distribution or re-use. @ Cambridge University Press and Australian and New Zealand Academy of Management 2019. 
Dissatisfied employees, diminished helping: Using psychological capital to buffer the damaging effects of job dissatisfaction on helping behaviours

Dirk De Clercq

Inam Ul Haq

Muhammad Umer Azeem

Paper accepted for publication in Journal of Management \& Organization 


\title{
Dissatisfied employees, diminished helping: Using psychological capital to buffer the damaging effects of job dissatisfaction on helping behaviours
}

\begin{abstract}
Drawing from conservation of resources theory, this study considers how employees' job dissatisfaction might reduce their engagement in helping behaviour, whereas their psychological capital might enhance this behaviour. The negative relationship between job dissatisfaction and helping behaviour in turn might be buffered by psychological capital. Data from Pakistani organizations provide empirical support for these theoretical predictions. The findings indicate that organizations with employees who feel unhappy about their job situation can still enjoy productive helping behaviours, to the extent they develop adequate personal resources within their ranks.
\end{abstract}

Keywords: helping behaviour; job dissatisfaction; psychological capital; conservation of resources theory 


\section{Introduction}

Management researchers underscore the important role of employees' positive efforts to assist other organizational members with their work, even when such efforts are not part of their formal job descriptions (Deckop et al., 2003; Imer, Kabasakal, and Dastmalchian, 2014; Liang et al., 2015; Peng and Zeng, 2017; Wei, 2012). Such helping behaviour reflects a critical component of the broader notion of organizational citizenship behaviour, whereby employees reach out to individual colleagues and spend time helping them with their job tasks (De Clercq et al., 2017; Kyei-Poku, 2014; Organ, 1988). Helping behaviour generally benefits its targets but also aids the organization overall and enhances the helpers' own personal well-being, by contributing to co-worker performance (Podsakoff et al., 1997), enhancing the organization's competitive advantage (Borman and Motowidlo, 1993), and generating a sense of personal fulfilment (Hoption, 2016; Lemoine et al., 2015).

Accordingly, there is consistent interest in determining which factors might stimulate or inhibit employees' decisions to devote significant time to voluntary helping behaviours. Positive factors that enable employees' helping behaviour include pro-social motives (Choi and Moon, 2016), a sense of belonging (Kyei-Poku, 2014), religion-based work values (De Clercq et al., 2017), team cohesion (Liang et al., 2015), co-worker support (Deckop et al., 2003), and authentic leadership (Hirst et al., 2016). Negative factors that inhibit helping behaviours instead include self-centred monetary motives (Tang et al., 2008), co-worker ostracism (Peng and Zeng, 2017), and open conflict norms (Rispens, 2009). Little research has been devoted to the specific question of how employees' lack of enthusiasm or excitement about their job situation might keep them from helping others though. 
This oversight is somewhat surprising, because unhappy feelings about work tend to deplete employees' energy and prevent them from fulfilling their job duties (Jiang et al., 2009; Rayton and Yalabik, 2014). Accordingly, this study proposes that the energy resource depletion that stems from feelings of unhappiness about their job situation may be so strong that it steers employees away from allocating discretionary energy toward helping activities that are not formally required. In addition to creating a deeper understanding of how employees respond to feelings of unhappiness, in the form of reduced helping behaviour, the study seeks to investigate useful ways in which organizations can contain this harmful effect, with a particular focus on the potential buffering effect of psychological capital. This critical personal resource captures the extent to which employees are confident in their own abilities, are hopeful about work goals, envision the future in a positive way, and are able to overcome workplace challenges (Luthans et al., 2007).

To anchor the theoretical arguments about the combined effects of job dissatisfaction and psychological capital on helping behaviour, this study draws on conservation of resources (COR) theory (Hobfoll, 1989, 2001). Accordingly, it postulates that the experience of negative feelings about their organization steers employees away from positive work behaviours, due to emotional resource depletion associated with these feelings (Hobfoll and Shirom, 2000; van Gelderen et al., 2017). When employees lack enthusiasm about their job situation for example, the frustration that they experience may limit the energy they have left to perform voluntary behaviours that could contribute to the well-being of other organizational members (De Clercq et al., 2017; Quinn et al., 2012), even if those behaviours also might benefit the organization or themselves (Borman and Motowidlo, 1993; Lemoine et al., 2015). But employees' access to relevant personal resources should tend to relate positively to their positive work behaviours, due to their 
energy-enhancing effect and the associated resource gains expected from such behaviours (Hobfoll, 2001; Mazzetti et al., 2016). Employees' psychological capital thus is a potentially critical personal resource with a direct positive relationship with helping behaviour. Finally, in line with COR theory, this study predicts an important buffering role of employees' personal resources, such that they help employees cope with adverse work conditions and mitigate energy depletion that arises in these conditions (Abbas et al., 2014; Hobfoll, 2001). That is, drained emotional energy resources due to an unhappy job situation might be countered by access to energy-enhancing psychological capital.

In short, this study contributes to extant research by examining an underexplored driver of employees' helping behaviour, namely, the lack of enthusiasm or excitement that they feel about their jobs (Jiang et al., 2009). Little research considers the possibility that the unhappy feelings employees might experience during the execution of their job tasks also can spill over to a reduced propensity to help their colleagues voluntarily, nor does extant literature offer predictions of how such challenges might be contained. Without such considerations, organizations lack a complete view of how negative behavioural reactions to dissatisfactory work situations might be countered by energy-enhancing resources that fuel people's ability to cope with workplace adversity (Hobfoll, 2001; Quinn et al., 2012). The current study thus offers managers important insights into (1) the challenges employees experience when they feel unhappy about their job situation, particularly in terms of their hesitance to reach out to colleagues and assist them voluntarily, as well as (2) how the possession of psychological capital among employees might mitigate this challenge.

\section{Research hypotheses}


Recent research highlights the need for more studies into how negative work situations may turn employees away from performing positive behaviours that are not strictly required by their job descriptions and for which they do not receive direct rewards (Cheung and Cheung, 2013; De Clercq and Belausteguigoitia, 2017; Peng and Zeng, 2017). These discretionary behaviours can be manifest in different shapes; they are not restricted to activities that directly improve organizational performance (Podsakoff et al., 2009). For example, helping activities aid organizations indirectly if employees reach out to individual peers and help them fulfil their job duties (Bachrach et al., 2016; Chou and Stauffer, 2016). This focus on individual-oriented helping behaviour acknowledges the important roles of collegial collaborations and social relationship building for the achievement of organizational effectiveness (Nahapiet and Ghoshal, 1998; Payne et al., 2011).

Figure 1 presents the conceptual framework and hypotheses for the current study. First, it relates employees' job dissatisfaction and psychological capital to the likelihood that they undertake helping behaviour. Second, the relationship between job dissatisfaction and helping behaviour should be moderated by psychological capital. In particular, and following COR theory (Hobfoll, 2001; Hobfoll and Shirom, 2000), job dissatisfaction likely diminishes and psychological capital enhances helping behaviour, but the former effect may be mitigated when employees can rely on high levels of psychological capital. Thus, psychological capital exerts not only a direct positive impact, in terms of fuelling helping behaviour, but also serves as a buffer against the harmful effects of job dissatisfaction, as detailed in the following sections.

[Insert Figure 1 about here]

\section{Job dissatisfaction and helping behaviour}


Many studies that predict helping behaviour focus on positive workplace factors as enablers (e.g., Hirst et al., 2016; Liang et al., 2015; Zhu and Akhtar, 2014); less attention has centred on the harmful effects of negative, resource-draining situations (Peng and Zeng, 2017; Pooja et al., 2016), including feelings of boredom or limited enthusiasm about the job. When employees are dissatisfied with or feel little enthusiasm about their jobs, it might constitute an important source of energy depletion that inhibits their helping behaviour, despite the various potential benefits of such behaviour (Jiang et al., 2009). Job dissatisfaction drains employees' positive emotional resources, so they feel frustrated and unhappy when they come to work (Little et al., 2011; Sun and Pan, 2008) and experience a diminished ability to meet job expectations (Rayton and Yalabik, 2014). Based on the logic of COR theory, this resource drainage should lead to a reduced propensity to undertake helping behaviours, reflecting a motivation to avoid further resource losses by conserving work-related energy, including energy that otherwise could be allocated to discretionary helping efforts (Hobfoll and Shirom, 2000; Ng and Feldman, 2012).

Similarly, employees who feel unhappy about their job situation tend to allocate their energy toward negative behaviours, such as reduced emotional attachment to their employer (Luna-Arocas and Camps, 2008) or higher rates of absenteeism (Frooman et al., 2012), instead of positive behaviours that could contribute to organizational effectiveness (Foote and Tang, 2008; Lu et al., 2013). The energy-draining effect that comes with a lack of enthusiasm about work thus translates into a certain passiveness at work, such that employees refrain from voluntarily contributing to the well-being of their co-workers (Hobfoll, 2001)

Hypothesis 1: There is a negative relationship between employees' job dissatisfaction and their helping behaviour.

\section{Psychological capital and helping behaviour}


In addition, employees' psychological capital—or the extent to which they exhibit high levels of self-efficacy, hope, optimism, and resilience (Luthans et al., 2007)—should influence their helping behaviours. Employees equipped with psychological capital (1) feel confident about their ability to perform their job duties, (2) have the energy to work hard toward goal attainment and the ability to see different pathways to such goal attainment, (3) expect positive outcomes for themselves in the future regardless of their personal ability, and (4) effectively bounce back from adverse situations (Avey et al., 2010; Luthans et al., 2007; Newman et al., 2014). These four components constitute an overarching construct, with a stronger impact on employee outcomes than each main effect of the components individually (Avey et al., 2011; Dawkins et al., 2013; Newman et al., 2014). For example, psychological capital as a whole has been shown to be a better predictor of job performance than its underlying components of self-efficacy, hope, optimism, or resilience (Luthans et al., 2007).

Employees' psychological capital may serve as an energy-enhancing personal resource, from which they can draw to engage in positive work behaviours (Luthans et al., 2007; Gupta et al., 2017), including voluntarily helping their colleagues. Discretionary helping efforts that assist colleagues with their job tasks require significant energy that might prevent employees from successfully fulfilling their regular job tasks (Bolino et al., 2015; Podsakoff et al., 2009), but employees who can rely on positive personal resource reservoirs are better able to persevere while undertaking work activities that consume significant energy but are not guaranteed to produce immediate rewards (Chen and Kao, 2011; Choi and Moon, 2016). Similarly, employees with high levels of psychological capital have greater confidence that the potential resource gains of their voluntary helping efforts—-such as higher quality peer relationships or useful peer feedback (Korsgaard et al., 2010)—are within reach (Newman et al., 2014), which should 
stimulate them to undertake such efforts, according to COR theory (Hobfoll, 2001). If employees instead cannot rely on high levels of psychological capital, they are less able to perform voluntary helping behaviours and more likely to allocate their energy solely to their regular job tasks (Avey et al., 2011; Gupta et al., 2017). Thus, psychological capital provides employees with the energy they need to help their colleagues on a voluntary basis and to persist in these efforts.

According to COR theory, possessing an energy-enhancing personal resource such as psychological capital also should motivate helping behaviours, which contribute to the generation of further resource gains in the form of personal fulfilment (Hobfoll and Shirom, 2000). For example, psychological capital creates a sense of personal meaningfulness if employees reach out to others and help them overcome work challenges (Avey et al., 2008). Employees who voluntarily help organizational colleagues with their job tasks thus may experience strong positive emotions when they are equipped with high psychological capital, such that they become particularly motivated to engage in discretionary helping behaviours (Hobfoll, 2001). Conversely, employees with less psychological capital tend to derive less personal fulfilment from undertaking activities that contribute to others' well-being (Avey et al., 2008). In this scenario, they have less to gain from undertaking voluntary helping activities; consistent with COR theory, their motivation to invest substantial energy in these helping activities thus should diminish (Hobfoll, 2001). Similarly, employees marked by low psychological capital tend to exhibit less commitment to their organization (Avey et al., 2011) and lower levels of work engagement (Joo et al., 2016), such that they would be less prone to help colleagues with their job tasks-activities that otherwise would benefit the employer (Podsakoff et al., 2009). 
Hypothesis 2: There is a positive relationship between employees' psychological capital and their helping behaviour.

\section{Moderating role of psychological capital}

Job dissatisfaction and psychological capital also might exert an interactive effect on helping behaviour, such that the negative link between job dissatisfaction and helping behaviour might be buffered or mitigated by psychological capital. According to COR theory, the harmful effect of resource-draining work conditions on positive work behaviours diminishes to the extent that employees have access to personal resources that compensate for their resource losses (Hobfoll, 2001; Hobfoll and Shirom, 2000). Psychological capital is one such personal resource that enables employees to find ways to cope with their unhappy feelings about their job situation (Abbas et al., 2014; Roberts et al., 2011). All four components may generate positive energy from which employees can draw to deal with their sense of dissatisfaction about their work situation (Gooty et al., 2009; Luthans et al., 2010): Self-efficacy may fuel confidence in their abilities to overcome the source of their dissatisfaction (Bandura, 1997); their hope may function as motivational driver to do well in their job tasks, even if confronted with a disappointing work situation (Snyder, 2002); optimism helps employees maintain a positive approach to their work (Seligman, 1998); and resilience enables employees to bounce back more easily from negative feelings about their job situation (Luthans, 2002).

Employees equipped with psychological capital also tend to feel motivated to seek solutions to adverse work situations (Avey et al., 2011; Newman et al., 2014), so undertaking extra-ordinary helping behaviours in the presence of negative feelings about their job may provide some personal fulfilment. The personal resource of psychological capital therefore could enhance not only employees' ability to cope with negative feelings about their job situation but 
also the personal joy they experience in this process (Hobfoll and Shirom, 2000). In a similar vein, employees marked by high psychological capital are strongly goal driven and exhibit high levels of goal commitment, particularly if the goals are challenging (Avey et al., 2008; Gupta et al., 2017). Their psychological capital thus may motivate employees to invest some energy in voluntary helping activities, even if such efforts cannot be taken for granted, because of how they feel about their own situation. Conversely, employees equipped with low psychological capital generally are less motivated to undertake challenging work activities, so they may devote less energy to discretionary helping efforts that are not formally required, if they already must deal with their lack of excitement or enthusiasm for their own work situation (Luthans et al., 2007).

Hypothesis 3: The negative relationship between employees' job dissatisfaction and their helping behaviour is moderated by their psychological capital, such that the relationship is weaker at higher levels of psychological capital.

\section{Research method}

\section{Data collection}

The data for this study came from several organizations in Pakistan that operate in different sectors, including textiles, food, telecom, finance, and education. The data collection process included two paper-and-pencil surveys: one administered with employees and another with the employees' supervisors. For both surveys, cover letters explained the purpose of the study and ensured complete confidentiality. In particular, participants were informed that the responses would be accessible only to the research team, that no employee-level information would ever be made available, and that any report or article generated from the study would be based on aggregated data only. Furthermore, the surveys emphasized that there were no right or 
wrong answers and urged participants to respond to the questions as honestly as possible - two measures that reduce concerns about social desirability or acquiescence biases (Spector, 2006). After they completed the surveys, the participants placed them in sealed envelopes and returned them directly to one of the authors. The participants were informed that the insights generated from the research would benefit their organization, but they did not receive any monetary or other incentive to participate. Furthermore, they were told that their participation was completely voluntary, and they could withdraw from the study at any time. Of the 500 surveys distributed, the 394 completed pairs reflect a response rate of $79 \%$. Among the respondents, $26 \%$ were women, and their average age was 28 years.

\section{Measures}

The measures of the three focal constructs used items derived from previous research.

Helping behaviour. To assess the likelihood that employees go out of their way to help their co-workers with their job, this study relied on a seven-item scale of helping behaviour, with seven-point Likert anchors, as developed by Williams and Anderson (1991) and applied in previous studies (e.g., Naseer et al., 2016; Raja and Johns, 2010). To avoid concerns about common method bias, supervisors provided the scores of employees' helping behaviours, on items such as, "This employee assists other employees with their work, even when not asked," “This employee takes time to listen to co-workers' problems and worries," and "This employee passes along information to co-workers" (Cronbach's alpha $=.88)$.

Job dissatisfaction. The job dissatisfaction measure was a reverse-coded, six-item scale of job satisfaction, using five-point Likert anchors (Abbas et al., 2014; Agho et al., 1992). Consistent with prior research (e.g., Jiang et al., 2009), this reverse-coded scale assesses the extent to which employees are unhappy with their job situation. One item in the original scale ("I 
am often bored with my job") already was worded to signal high levels of dissatisfaction. It combined with reverse-coded versions of items such as "I find real enjoyment in my work," and "Most days I am enthusiastic about my work" (Cronbach's alpha $=.83$ ).

Psychological capital. For the measure of employees' self-assessed psychological capital, this study adopted the 24-item Psychological Capital Questionnaire (PCQ; Luthans et al., 2007), with six-point Likert anchors, as has been validated in previous studies (e.g., Avey et al., 2006; Gooty et al., 2009; Luthans et al., 2008; Roberts et al., 2011). The scale includes questions pertaining to self-efficacy (e.g., "I feel confident discussing my work area with the management"), hope (e.g., "I can think of many ways to reach my current work goals"), optimism (e.g., "I always look on the bright side of things regarding my job"), and resilience (e.g., "I usually manage difficulties one way or another at work"). A second-order confirmatory factor analysis confirmed that the four dimensions loaded on the psychological capital construct as a second-order factor. The paths between the second-order factor and each of the first-order factors were strongly significant $(p<.001)$, and the second-order model exhibited a good fit (confirmatory fit index $=.91 ;$ Tucker-Lewis index $=.90 ;$ incremental fit index $=.92 ;$ root mean square error of approximation $=.05$ ). The internal consistency of the 24-item measure was high (Cronbach's alpha $=.87)$, and the treatment of psychological capital as an overarching construct is consistent with previous empirical studies (e.g., Avey et al., 2008; Roberts et al., 2011),

Control variables. The regression analyses included two control variables, gender $(1=$ female) and age (in years).

\section{Results}

Table 1 contains the zero-order correlations and descriptive statistics, and Table 2 reports the regression results. Model 1 included the control variables, Model 2 added job dissatisfaction 
and psychological capital, and Model 3 added the job dissatisfaction $\times$ psychological capital interaction term, after mean-centring its constitutive components (Aiken and West, 1991).

[Insert Tables 1 and 2 about here]

Model 1 revealed that helping behaviours were higher among female than male employees $(\beta=.328, p<.05)$ and among older employees $(\beta=.021, p<.05)$. In support of the theoretical prediction that employees who feel unhappy about their job situations are less likely to assist their co-workers voluntarily, Model 2 indicated a negative relationship between job dissatisfaction and helping behaviour $(\beta=-.476, p<.001$, Hypothesis 1$)$. Model 2 also showed support for a beneficial role of psychological capital, in that employees equipped with higher levels of psychological capital were more likely to undertake helping behaviour $(\beta=.252, p<$ $.01)$, in support of Hypothesis 2.

Model 3 indicated support for the theorized buffering effect of psychological capital on the negative relationship between job dissatisfaction and helping behaviour $(\beta=.179, p<.05)$. The extent to which job dissatisfaction diminished helping behaviour was mitigated among employees with higher levels of psychological capital, in support of Hypothesis 3. To depict the nature of this moderating effect, Figure 2 contains a plot of the effects of job dissatisfaction on helping behaviour at high and low levels of psychological capital, combined with a simple slope analysis (Aiken and West, 1991). The relationship between job dissatisfaction and helping behaviour was strongly significant when psychological capital was low $(\beta=-.641, p<.001)$ but only weakly significant when it was high $(\beta=-.283, p<.10)$, in further support of Hypothesis 3 .

[Insert Figure 2 about here]

\section{Discussion}


Prior research points to the importance of investigating how employees' positive energy can be channelled into discretionary work behaviours that contribute to organizational effectiveness but that are not formally required (e.g., Choi and Moon, 2016; Lin and Peng, 2010). These extra-role behaviours are not restricted to activities that directly add to organizational performance but also can manifest indirectly through employees' efforts to reach out to individual colleagues and facilitate the successful completion of their job tasks (Chou and Stauffer, 2016). Our focus on such helping behaviour, instead of organizational citizenship in general, acknowledges the critical role of productive positive interpersonal interactions for organizational well-being (Bachrach et al., 2006). Yet allocating substantial time to voluntary work activities also has a negative side; it might be distracting for employees and prevent them from fulfilling their formal job duties (Bolino et al., 2015). Thus, this study addresses the pertinent issue of how a negative, resource-draining job situation might steer employees away from helping behaviour - behaviour that already is inherently challenging.

In particular, and drawing from COR theory (Hobfoll, 1989, 2001), this research has investigated the roles of job dissatisfaction and psychological capital in predicting helping behaviour. The central predictions assert that employees' negative feelings about their job, as manifest in a lack of enthusiasm or excitement, may undermine their propensity to reach out to their co-workers and assist them in their work, yet this effect may be mitigated by the extent to which employees are equipped with psychological capital. In particular, this personal resource may fuel helping behaviour directly, and it also may make employees more immune to the emotional resource drainage that stems from unhappy work feelings, thereby reducing the likelihood that employees become reluctant to help their peers (Abbas et al., 2014). The empirical findings confirm these theoretical predictions. 
The direct positive relationship between job dissatisfaction and helping behaviour, as found herein, is consistent with the argument that employees' experience of negative job-related feelings compromises their extra-role helping behaviours, from which the employer and its members otherwise could benefit (Ng and Van Dyne, 2005; Rispens, 2009). A critical mechanism that explains this process, based on COR theory, is the desire to conserve positive work-related energy (Hobfoll, 2001). That is, employees who do not feel enthusiastic about their current job situation may prefer to save their personal energy resources for behaviours that generate immediate returns (i.e., meeting their job requirements), instead of going out of their way to perform extra-role helping activities that are not formally rewarded (Jiang et al., 2009). In turn, the direct positive relationship between psychological capital and helping behaviour shows that employees who are equipped with positive, energy-enhancing personal resources tend to be more supportive of their co-workers. This personal resource entails four psychological capacities—self-efficacy, hope, optimism, and resiliency—which infuse employees with positive energy that steers them toward activities that support organizational success and improvement (Luthans et al., 2007; Newman et al., 2014). From a conceptual perspective, the positive relationship between psychological capital and helping behaviour is also consistent with COR theory (Hobfoll, 1989; Hobfoll and Shirom, 2000), in that employees equipped with this personal resource have greater confidence that they can be effective in their helping efforts and anticipate possible resource gains in the form of useful peer feedback and reciprocity, for example (Hui et al., 2000; Korsgaard et al, 2010). Moreover, psychological capital may spur helping behaviour, due to the feelings of personal fulfilment it can generate (Avey et al., 2011). 
The core insight that arises from this study though is that psychological capital also has a more covert beneficial role: It serves as a buffer against the negative effects of employees' job dissatisfaction on helping behaviour. The likelihood that employees avoid assisting co-workers because they hold negative emotions about their job situation diminishes, to the extent that the associated resource depletion can be countered by their psychological capital (Hobfoll, 2001). Psychological capital fuels employees' energy levels, so they can better cope with the frustration that arises in unfavourable work situations (Abbas et al., 2014; Rehman et al., 2017), as well as reserve some of their resources to support discretionary helping activities that are not formally required (De Clercq and Belausteguigoitia, 2017). Moreover, employees with high psychological capital experience personal joy from undertaking helping behaviours in the presence of adverse work situations, which thwarts the likelihood that they withhold such positive behaviours because of their own frustration (Newman et al., 2014). When they can draw on their psychological capital, employees are better equipped to undertake voluntary behaviours that contribute to the success of their colleagues, even if they are not completely happy about their own job situation.

Notably, our conceptual focus on the mitigating role of employees' psychological capital touches on the incremental role of job dissatisfaction, such that the study's central contribution pertains to the relative usefulness of employees' possession of valuable personal resources for preventing their unhappy job feelings from halting their helping activities. From an empirical standpoint, this issue manifests in slope differences at different levels of psychological capital. As the interaction plot in Figure 2 and the associated simple slope analysis reveal, increasing levels of job dissatisfaction diminish helping behaviours only minimally when employees are equipped with high levels of this personal resource. Alternatively, employees' lack of enthusiasm 
represents an important inhibitor of their voluntary assistance of coworkers, in the absence of sufficient psychological capital.

Even though the study's theoretical arguments are not country-specific, cultural factors may be relevant, in light of the specific empirical setting of Pakistan, which entails two key opposing forces. On the one hand, the high level of collectivism that marks Pakistani culture, with its focus on maintaining group harmony (Hofstede et al., 2010), may cause employees to feel somewhat "forced" to go out of their way to assist peers who ask for help, even when those employees face a negative job situation themselves. From this perspective, the roles of job dissatisfaction and psychological capital for explaining helping behaviour would be relatively weak or absent. On the other hand, the uncertainty avoidance that is inherent to Pakistani culture (Hofstede et al., 2010) might mean that employees feel strongly and negatively affected by the uncertainties that come with an unhappy job situation. Following this logic, the experience of resource-draining job dissatisfaction should be an important inhibitor of their helping behaviour, and the value of their psychological capital in mitigating this process should be salient. This post hoc reasoning about the possible role of different cultural factors clearly warrants caution, but the empirical support for the hypotheses indicates that the role of uncertainty avoidance might prevail over that of collectivism.

Overall, the study's findings extend management research by elaborating on the interplay of sources of energy depletion (job dissatisfaction) and energy creation (psychological capital) that informs employees' propensity to help their colleagues with their jobs. The scope of the tested model is somewhat narrow, reflecting the research goal of achieving depth, rather than breadth, by focusing on how resource depletion due to unhappy feelings about one's job situation might be contained by the critical personal resource of psychological capital. Consistent with 
COR theory (Hobfoll and Shirom, 2000), employees' reliance on psychological capital mitigates the likelihood that they choose not to assist their co-workers in response to the emotional resource drainage caused by job dissatisfaction — a positive role that has not been investigated in previous studies. In so doing, this study adds the important insight that the harmful role of an unhappy job situation in curtailing helping behaviours can be contained by an energy-enhancing personal resource, such as psychological capital, that counters the hardships of such a situation. To the extent that employees can draw from enhanced levels of self-efficacy, hope, optimism, and resilience, they are better positioned to manage the frustration that comes with their limited job-related enthusiasm, so they retain sufficient energy to help their co-workers with their job duties.

\section{Limitations and future research}

Despite its merits, this study also has some limitations, which suggest avenues for further research. First, we theorized that employees' desire to conserve positive work energy is an important mechanism that underpins the negative relationship between their job dissatisfaction and helping behaviour, but we do not empirically assess this mechanism. Further research could do so. In a related vein, we measured helping behaviour with supervisor ratings to avoid concerns about common method bias. Nonetheless, it would be useful to check for agreement among employees, peers, and supervisors in terms of how much, or little, effort employees dedicate to helping activities, as well as whether any differences in these ratings reflect how employees feel about their job situation.

Second, the focus on a specific, important, contingency factor excludes alternative potential buffers of the harmful effect of job dissatisfaction on helping behaviours. Other personal factors could function as buffers, including employees' passion for work (Baum and 
Locke, 2004) or learning orientation (VandeWalle et al., 1999)_factors that each may compensate for the emotional resource drainage that employees experience when they feel bored and lack enthusiasm about their job situation. Moreover, positive organizational factors might counter the resource depletion that arises with job dissatisfaction, such as perceived organizational support (Wayne et al., 1997), transformational leadership (Zhu and Akhtar, 2014), or perceptions of organizational fairness (Colquitt et al., 2001). Another related extension might investigate alternative theoretical models, such as a model that conceives of psychological capital as a mediator between job dissatisfaction and helping behaviours or else a moderated mediation model that assesses whether the interactive effect of job dissatisfaction and psychological capital on helping behaviour might be mediated by emotional exhaustion or organizational commitment.

Third, and as mentioned, the arguments leading to the research hypotheses are country neutral, yet the country context of Pakistan is interesting in that its collectivism and uncertainty avoidance dimensions might have opposing influences on the predicted relationships. The empirical results suggest a more prominent role of uncertainty avoidance-employees' psychological capital serves as a buffer that enables employees to retain some energy for their helping behaviours in the presence of uncertainty-inducing job dissatisfaction (Hobfoll and Shirom, 2000) — but it also would be useful to undertake multi-country comparisons to explicate the relative importance of job dissatisfaction for thwarting helping behaviours, as well as the potency of various underlying moderators to buffer this process, across different cultural contexts. Yet another extension might examine the role of pertinent cultural values at the individual level, such as employees' collectivistic orientation (Triandis and Gelfland, 1998) or risk aversion (Allen et al., 2005). 


\section{Practical implications}

This research has important implications for managerial practice. In particular, the study's results underscore the challenge that managers interested in spurring voluntary helping efforts face when they count unhappy employees within their ranks, as well as the useful role that the personal resource of psychological capital can have in this case. When they lack enthusiasm or excitement about their job situation, employees feel unhappy; managers should seek to mitigate this situation. Notable in this regard is that some employees may be hesitant to admit that they feel unhappy about their job situation, to avoid appearing overly complaining or ungrateful. Managers therefore should be proactive in identifying employees who suffer from job dissatisfaction and pinpoint the reasons (e.g., unmet expectations, excessive workloads, destructive leadership). They also could help employees recognize feelings of unhappiness in others and devise open knowledge sharing routines about such issues. By organizing customized training initiatives that stimulate open communication, they could encourage employees to express their disappointment with specific elements of their job situation (Cabrera and Cabrera, 2005). Such initiatives could feature formalized programs that take place outside the workplace, as well as informal, on-the-job learning methods, each of which represent useful pathways for professional development (Enos et al., 2003). Ultimately, the initiatives may contribute to maintaining a helping culture in organizations, to the extent that they facilitate in-depth discussions about possible sources of employee unhappiness and solutions for dealing with the negative feelings that result.

Yet some level of unhappiness within employee ranks may be unavoidable. The current study indicates that employees who can rely on higher levels of psychological capital—feel confident about their own abilities, are hopeful about achieving work goals, are optimistic about 
their future, and are resilient when bouncing back from failure (Luthans et al., 2007) — are better prepared to cope with the hardship that comes with an unsatisfactory job situation. That is, employees' psychological capital is a useful personal resource that managers can leverage to mitigate resource depletion due to job dissatisfaction, thereby freeing residual energy for voluntary helping behaviours, even in an unfavourable situation. A specific recommendation arising from this research thus highlights the value of recruiting and retaining employees who are equipped with high levels of psychological capital.

In addition to recruiting and retaining employees with high psychological capital, organizations can develop this personal resource among their employee bases (Luthans, 2002). To spur employees' psychological capital, they could explain, for example, which specific skills and mind sets are most needed to cope effectively with difficult work situations. They also might feature successful role models who have exhibited their ability to help co-workers in need, even when they do not operate in ideal work circumstances. Because the personal resource of psychological capital is malleable and open to development, it can be promoted in relatively short training sessions (Luthans et al., 2010) or even online programs (Luthans et al., 2008). Despite the great value of treating psychological capital as an overarching construct (Newman et al., 2014), it also may be useful to assess explicitly how employees score on each of its underlying dimensions, then develop targeted approaches to address any deficiencies (Dawkins et al., 2013). Ultimately, employees may become more confident about their ability to cope with imperfect work situations to the extent that they develop adequate personal capacities that fuel their energy levels, as manifest in increases in the different components that underpin their psychological capital.

\section{Conclusion}


This study contributes to extant research by investigating the unexplored, combined effects of job dissatisfaction and psychological capital for predicting helping behaviour. The paucity of research on this topic is somewhat surprising, especially in light of the recognition that allocating time to voluntary helping activities usurps significant energy (Podsakoff et al., 2009) and can be a challenge for employees who face unfavourable work conditions or are deprived of adequate personal resources (Choi and Moon, 2016; Peng and Zeng, 2017). Using COR theory as a conceptual framework, this study reveals that job dissatisfaction inhibits helping behaviour, and psychological capital stimulates such behaviour. Moreover, withholding helping behaviour, as a response to the emotional resource depletion that comes with job dissatisfaction, is mitigated to the extent that employees can draw from their psychological capital. For organizations, this study thus establishes a revised, expanded understanding of the occurrence of extra-role helping behaviours within their ranks. For scholars, these findings can serve as catalysts for further studies into how organizational leaders might stimulate voluntary helping behaviours among employees, even in the presence of resource-draining feelings or frustration. 


\section{References}

Abbas, M., Raja, U., Darr, W., and Bouckenooghe, D. (2014). Combined effects of perceived politics and psychological capital on job satisfaction, turnover intentions, and performance. Journal of Management, 40, 1813-1830.

Agho, A. O., Price, J. L., and Mueller, C. W. (1992). Discriminant validity of measures of job satisfaction, positive affectivity, and negative affectivity. Journal of Occupational Psychology, 65, 185-196.

Aiken, L.S., and West, S.G. (1991). Multiple regression: Testing and interpreting interactions. Newbury Park, CA: Sage.

Allen, D.G., Weeks, K.P., and Moffitt, K.R. (2005). Turnover intentions and voluntary turnover: The moderating roles of self-monitoring, locus of control, proactive personality, and risk aversion. Journal of Applied Psychology, 90, 980-990.

Avey, J.B., Luthans, F., and Youssef, C.M. (2010). The additive value of psychological capital in predicting workplace attitudes and behaviors. Journal of Management, 36, 430-452.

Avey, J.B., Patera, J.L., and West, B.J. (2006). Positive psychological capital: A new approach for understanding absenteeism. Journal of Leadership and Organizational Studies, 13, 4260.

Avey, J.B., Reichard, R.J., Luthans, F., and Mhatre, K.H. (2011). Meta-analysis of the impact of positive psychological capital on employee attitudes, behaviours, and performance. Human Resource Development Quarterly, 22, 127-152

Avey, J.B., Wernsing, T.S., and Luthans, F. (2008). Can positive employees help positive organizational change? Impact of psychological capital and emotions on relevant attitudes and behaviours. Journal of Applied Behavioural Science, 44, 48-70. 
Bachrach, D.G., Powell, B.C., Collins, B.J., and Richey, R.G. (2006). Effects of task interdependence on the relationship between helping behaviour and group performance. Journal of Applied Psychology, 91(6), 1396-1405.

Bandura, A. (1997). Self-efficacy: The exercise of control, Freeman, New York.

Baum, J.R., and Locke, E.A. (2004). The relationship of entrepreneurial traits, skill, and motivation to subsequent venture growth. Journal of Applied Psychology, 89, 587-598.

Bolino, M.C., Hsiung, H.-H., Harvey, J., and LePine, J.A. (2015). Well, I'm tired of tryin’! Organizational citizenship behavior and citizenship fatigue. Journal of Applied Psychology, $100,56-74$.

Borman, W. C., and Motowidlo, S. J. (1993) . Expanding the criterion domain to include elements of contextual performance. In N. Schmitt and W. C. Borman (Eds.), Personnel selection in organizations (pp. 71-98). San Francisco: Jossey-Bass.

Cabrera, E. F., and Cabrera, A. (2005). Fostering knowledge sharing through people management practices. International Journal of Human Resource Management, 16, 720-735.

Chen, C.-H. V., and Kao, R.-H. (2011). A multilevel study on the relationships between work characteristics, self-efficacy, collective efficacy, and organizational citizenship behavior: The case of Taiwanese police duty-executing organizations. Journal of Psychology, 145, 361390.

Cheung, F.Y.-L., and Cheung, R.Y.-H. Effect of emotional dissonance on organizational citizenship behaviour: Testing the stressor-strain-outcome model. Journal of Psychology, 147, 89-103.

Choi, B.K., and Moon, H. (2016). Prosocial motive and helping behaviour: examining helping efficacy and instrumentality. Journal of Managerial Psychology, 31(2), 359-374. 
Chou, S. Y., and Stauffer, J. M. (2016). A theoretical classification of helping behaviour and helping motives. Personnel Review 45, 871-888.

Colquitt, J.A., Conlon, D.E., Wesson, M.J., Porter, C.O.L.H., and Ng, K.Y (2001). Justice at the millennium: a meta-analytic review of 25 years of organizational justice research. Journal of Applied Psychology, 86, 425-445.

Dawkins, S., Martin, A., Scott, J., and Sanderson, K. (2013). Building on the positives: A psychometric review and critical analysis of the construct of psychological capital. Journal of Occupational and Organizational Psychology, 86, 348-370.

De Clercq, D., and Belausteguigoitia, I. (2017). Mitigating the negative effect of perceived organizational politics on organizational citizenship behaviour: Moderating roles of contextual and personal resources. Journal of Management and Organization, 23, 689-708.

De Clercq, D., Rahman, Z., and Haq, I.U. (2017). Explaining helping behaviour in the workplace: The interactive effect of family-to-work conflict and Islamic work ethic. Journal of Business Ethics, doi: 10.1007/s10551-017-3541-3.

Deckop, J.R., Cirka, C.C., and Andersson, L.M. (2003). Doing unto others: The reciprocity of helping behaviour in organizations. Journal of Business Ethics, 47(2), 101-113.

Eatough, E. M., Chang, C. H., Miloslavic, S.A., and Johnson, R. E. (2011). Relationships of role stressors with organizational citizenship behaviour: A meta-analysis. Journal of Applied Psychology, 96, 619-632.

Enos, M.D., Kehrhahn, M.T., and Bell, A. (2003). Informal learning and the transfer of learning: How managers develop proficiency. Human Resource Development Quarterly, 14, 368-387. 
Foote, D.A., and Tang, T.L.-P. (2008). Job satisfaction and organizational citizenship behaviour (OCB): Does team commitment make a difference in self-directed teams? Management Decision, 46, 933-947.

Frooman, J., Mendelson, M.B., and Murphy, J.K. (2012). Transformational and passive avoidant leadership as determinants of absenteeism. Leadership and Organization Development Journal, 33, 447-463.

Gooty, J., Gavin, M., Johnson, P.D., Frazier, M.L., and Snow, D.B. (2009). In the eyes of the beholder: Transformational leadership, positive psychological capital, and performance. Journal of Leadership and Organizational Studies, 15, 353-367.

Gupta, M., Shaheen, M., and Reddy, P.K. (2017). Impact of psychological capital on organizational citizenship behaviour: Mediation by work engagement. Journal of Management Development, 36, 973-983.

Hirst, G., Walumbwa, F., Aryee, S., Butarbutar, I., and Chen, C.J. (2016). A multi-level investigation of authentic leadership as an antecedent of helping behaviour. Journal of Business Ethics, 139, 485-499.

Hobfoll, S.E. (1989). Conservation of resources. A new attempt at conceptualizing stress. American Psychologist, 44, 513-524.

Hobfoll, S.E. (2001). The influence of culture, community, and the nested-self in the stress process: Advancing conservation of resource theory. Applied Psychology: An International Review, 50, 337-369.

Hobfoll, S.E., and Shirom, A. (2000). Conservation of resources theory: Applications to stress and management in the workplace. In R.T. Golembiewski (Ed.), Handbook of organization behaviour (2nd ed., pp. 57-81). New York: Dekker. 
Hofstede, G.H., Hofstede, G.J., and Minkov, M. (2010). Cultures and organizations: Software of the mind. Intercultural cooperation and its importance for survival ( $3^{\text {rd }}$ ed.). New York: McGraw-Hill.

Hoption, C. (2016). The double-edged sword of helping behaviour in leader-follower dyads. Leadership and Organization Development Journal, 37(1), 13-41.

Hui, C., Lam, S. S. K., and Law, K. K. S. (2000). Instrumental values of organizational citizenship behaviour for promotion: A field quasi-experiment. Journal of Applied Psychology, 85, 822-828.

Imer, P.H., Kabasakal, H., and Dastmalchian, A. (2014). Personality and contextual antecedents of organizational citizenship behavior: A study of two occupational groups. Journal of Management \& Organization, 20, 441-462.

Jacobs, R.L. (2003), Structured on-the-job training: Unleashing employee expertise in the workplace. Berrett-Koehler, San Francisco, CA.

Jiang, B., Baker, R.C., and Frazier, G.V. (2009). An analysis of job dissatisfaction and turnover to reduce global supply chain risk: Evidence from China. Journal of Operations Management, 27, 169-184.

Joo, B.-K., Lim, D.H., and Kim, S. (2016). Enhancing work engagement: The roles of psychological capital, authentic leadership, and work empowerment. Leadership and Organization Development Journal, 37, 1117-1134.

Korsgaard, M.A., Meglino, B.M., Lester, S.W., and Jeong, S.S. (2010). Paying you back or paying me forward: Understanding rewarded and unrewarded organizational citizenship behaviour. Journal of Applied Psychology, 95, 277-290. 
Kyei-Poku, I. (2014). The benefits of belongingness and interactional fairness to interpersonal citizenship behaviour. Leadership and Organization Development Journal, 35, 691-709.

Lemoine, G.J., Parsons, C.K., and Kansara, S. (2015). Above and beyond, again and again: Selfregulation in the aftermath of organizational citizenship behaviours. Journal of Applied Psychology, 100, 40-55.

Liang, H.-Y., Shih, H.-A., and Chiang, Y.-H. (2015). Team diversity and team helping behaviour: The mediating roles of team cooperation and team cohesion. European Management Journal, 33(1), 48-59.

Lin, C.-C., and Peng, T.-K. (2010). From organizational citizenship behaviour to team performance: The mediation of group cohesion and collective efficacy. Management and Organization Review, 6, 55-75.

Little, L.M., Nelson, D.L., Quade, M.J., and Ward, A. (2011). Stressful demands or helpful guidance? The role of display rules in Indian call centers. Journal of Vocational Behavior, 79, 724-733.

Lu, C.-J., Shih, Y.-Y., and Chen, Y.-L. (2013). Effects of emotional labor and job satisfaction on organizational citizenship behaviors: A case study on business hotel chains. International Journal of Organizational Innovation, 5, 165-176.

Luna-Arocas, R., and Camps, J. (2008). A model of high performance work practices and turnover intentions. Personnel Review, 37, 26-46.

Luthans F. (2002). Positive organizational behaviour: Developing and managing psychological strengths. Academy of Management Executive, 16, 57-72. 
Luthans, F., Avey, J. B., Avolio, B. J., and Peterson, S. J. (2010). The development and resulting performance impact of positive psychological capital. Human Resource Development Quarterly, 21, 41-67.

Luthans, F., Avey, J. B., and Patera, J. L. (2008). Experimental analysis of a web-based training intervention to develop positive psychological capital. Academy of Management Learning and Education, 7, 209-221.

Luthans, F., Avolio, B.J., Avey, J., and Norman, S. (2007). Positive psychological capital: Measurement and relationship with performance and satisfaction. Personnel Psychology, 60, $541-572$.

Luthans, F., Avolio, B., Walumbwa, F., and Li, W. (2005). The psychological capital of Chinese workers: Exploring the relationship with performance. Management and Organization Review, 1, 249-271

Luthans, F., Norman, S. M., Avolio, B. J., and Avey, J. B. (2008). The mediating role of psychological capital in the supportive organizational climate-employee performance relationship. Journal of Organizational Behaviour, 29, 219-238.

Luthans, F., and Youssef, C.M. (2007). Emerging positive organizational behaviour. Journal of Management 33, 321-349.

Mazzetti, G., Guglielmi, D., Chiesa, R., and Mariani, M.G. (2016). Happy employees in a resourceful workplace: just a direct relationship? A study on the mediational role of psychological capital. Career Development International, 21, 682-696.

Nahapiet, J. and Ghoshal, S. (1998). Social capital, intellectual capital, and the organizational advantage. Academy of Management Review, 23, 242-268. 
Naseer, S., Raja, U., Syed, F., Donia, M.B.L., and Darr, W. (2016). Perils of being close to a bad leader in a bad environment: Exploring the combined effects of despotic leadership, leader member exchange, and perceived organizational politics on behaviours. The Leadership Quarterly, 27, 14-33.

Newman, A., Ucbasaran, D., Zhu, F., and Hirst, G. (2014). Psychological capital: A review and synthesis. Journal of Organizational Behaviour, 35, S120-S138.

Ng, T.W.H., and Feldman, D.C. (2012). Employee voice behaviour: A meta-analytic test of the conservation of resources framework. Journal of Organizational Behaviour, 33, 216-234.

Ng, K.Y., and Van Dyne, L. (2005). Antecedents and performance consequences of helping behavior in work groups: A multilevel analysis. Group \& Organization Management, 30(5), $514-540$.

Organ, D. W. (1988). Organizational citizenship behaviour: The good soldier syndrome. Lexington Books, Lexington, MA.

Payne, G.T., Moore, C.B., Griffis, S.E., and Autry, C.W. (2011). Multilevel challenges and opportunities in social capital research. Journal of Management, 37, 491-520.

Peng, A.C., and Zeng, W. (2017). Workplace ostracism and deviant and helping behaviours: The moderating role of 360 degree feedback. Journal of Organizational Behaviour, 38, 833-855.

Podsakoff, P.M., Ahearne, M., MacKenzie, S.B. (1997). Organizational citizenship behaviour and the quantity and quality of work group performance. Journal of Applied Psychology, $82(2), 262-270$

Podsakoff, N.P., Whiting, S.W., Podsakoff, P.M., and Blume, B.D. (2009). Individual-and organizational-level consequences of organizational citizenship behaviors: A meta-analysis. Journal of Applied Psychology, 94, 122-141. 
Pooja, A.A., De Clercq, D., and Belausteguigoitia, I. (2016). Job stressors and organizational citizenship behaviour: The roles of organizational commitment and social interaction. Human Resource Development Quarterly, 27, 373-405.

Quinn, R.W., Spreitzer, G.M., and Lam, C.F. (2012). Building a sustainable model of human energy in organizations: Exploring the critical role of resources. Academy of Management Annals, 6, 337-396.

Raja, U., and Johns, G. (2010). The joint effects of personality and job scope on in-role performance, citizenship behaviours, and creativity. Human Relations, 63, 985-1007.

Rayton, B.A., and Yalabik, Z.Y. (2014). Work engagement, psychological contract breach and job satisfaction. International Journal of Human Resource Management, 25, 2382-2400.

Rehman, S.U., Qingren, C., Latif, Y., and Iqbal, P. (2017). Impact of psychological capital on occupational burnout and performance of faculty members. International Journal of Educational Management, 31, 455-469.

Rispens, S. (2009). Do fights prohibit helping? The influence of task interdependence and conflict norms on helping behavior during task conflict. International Journal of Conflict Management, 20, 158-172.

Roberts, S.J., Scherer, L.L., and Bowyer, C.J. (2011). Job stress and incivility: What role does psychological capital play? Journal of Leadership and Organizational Studies, 18, 449-458.

Seligman, M. E. P. (1998). Learned optimism. Pocket Books, New York.

Snyder, C. R. (2002). Hope theory: Rainbows in the mind. Psychological Inquiry, 13, 249-275.

Spector, P.E. (2006). Method variance in organizational research: Truth or urban legend? Organizational Research Methods, 9, 221-232. 
Sun, L.-Y., and Pan, W. (2008). HR practices perceptions, emotional exhaustion, and work outcomes: A conservation-of-resources theory in the Chinese context. Human Resource Development Quarterly, 19, 55-74.

Tang, T.L.-P., Sutarso, T., Wu Davis, G M.-T., Dolinski, D., Ibrahim, A.H.S., and Wagner, S.L. (2008). To help or not to help? The Good Samaritan effect and the love of money on helping behaviour. Journal of Business Ethics, 82, 865-887.

Triandis, H.C, and Gelfand, M.J. (1998). Converging measurement of horizontal and vertical individualism and collectivism. Journal of Personality and Social Psychology, 74, 118-128.

VandeWalle, D., Brown, S.P., Cron, W.L., and Slocum J.W. (1999). The influence of goal orientation and self-regulation tactics on sales performance: A longitudinal field test. Journal of Applied Psychology 84, 249-259.

van Gelderen, B.R., Konijn, E.A., and Bakker, A.B. (2017). Emotional labor among police officers: a diary study relating strain, emotional labor, and service performance. International Journal of Human Resource Management, 28, 852-879.

Wayne, S.J., Shore, L.M., and Liden, R.C. (1997). Perceived organizational support and leadermember exchange: A social exchange perspective. Academy of Management Journal, 40, 82111.

Wei, Y.-C. (2012). Person-organization fit and organizational citizenship behavior: Time perspective. Journal of Management \& Organization, 18, 833-844.

Williams, L.J., and Anderson, S.E. (1991). Job satisfaction and organizational commitment as predictors of organizational citizenship and in-role behaviours. Journal of Management, 17, $601-617$. 
Zhu, Y., and Akhtar, S. (2014). How transformational leadership influences follower helping behaviour: The role of trust and prosocial motivation. Journal of Organizational Behaviour, 35(3), 373-392. 
Figure 1: Conceptual model

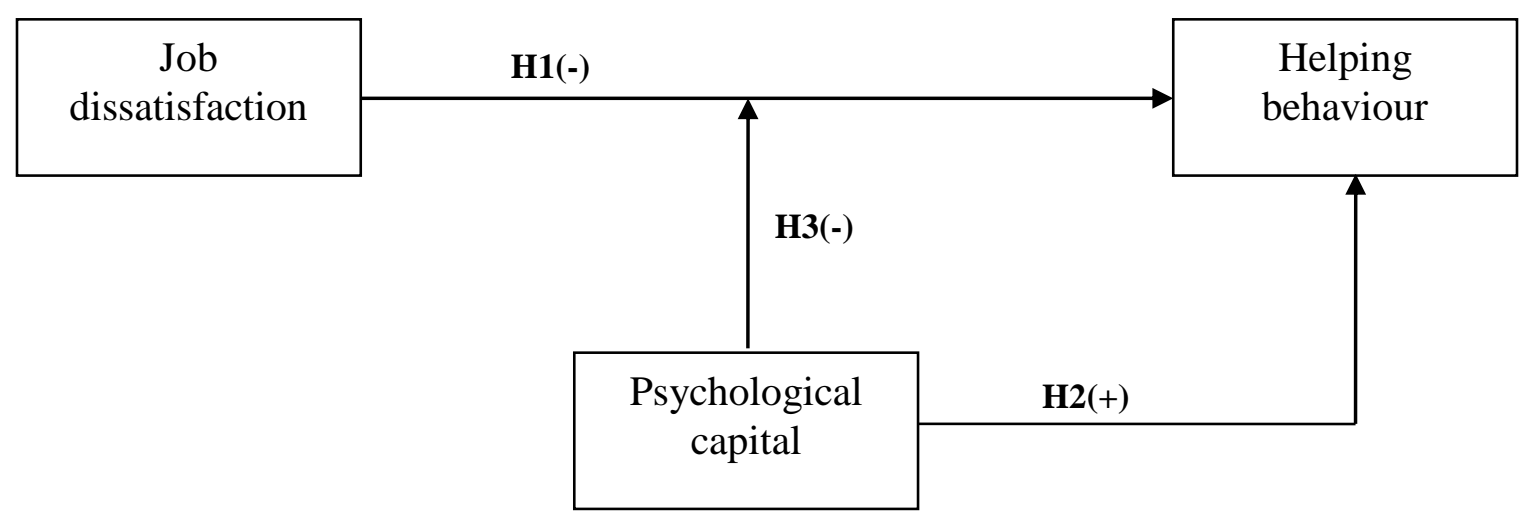


Figure 2: Moderating effect of psychological capital on the relationship between job dissatisfaction and helping behaviour

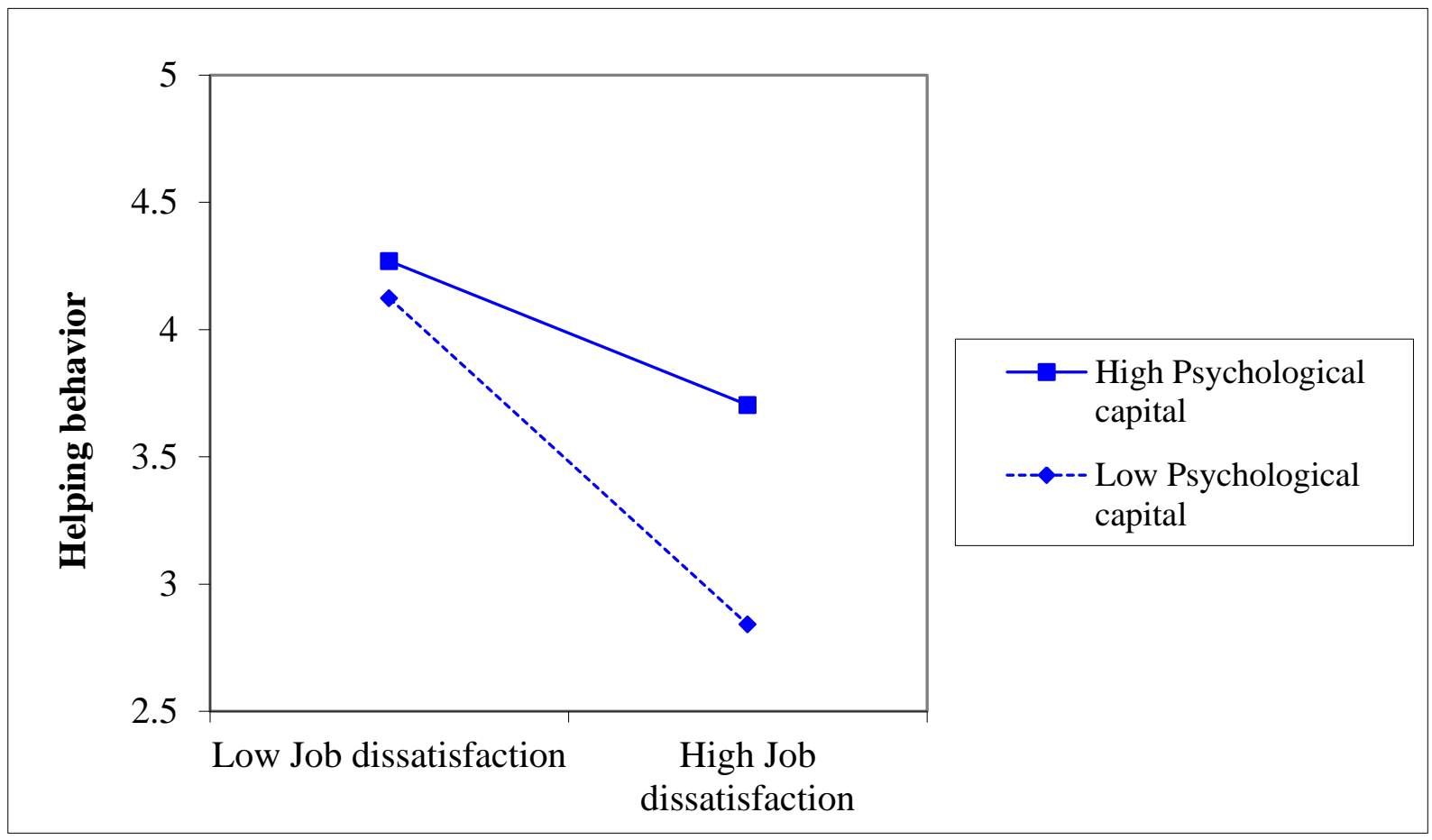


Table 1: Correlation table and descriptive statistics

\begin{tabular}{lcccccc}
\hline & Mean & SD & 1 & 2 & 3 & 4 \\
\hline 1. Helping behaviour & 4.328 & 1.242 & & & & \\
2. Job dissatisfaction & 2.542 & .825 & $-.358^{* *}$ & & & \\
3. Psychological capital & 4.090 & .723 & $.234^{* *}$ & $-.225^{* *}$ & & \\
4. Gender & .264 & .441 & $.100^{*}$ & -.058 & $.130^{* *}$ & \\
5. Age & 28.393 & 6.202 & .087 & -.089 & $.134^{* *}$ & $-.155^{* *}$ \\
\hline
\end{tabular}

Notes: $\mathrm{N}=394$.

$* * p<.01 ; * p<.05$. 
Table 2: Regression results (dependent variable: helping behaviour)

\begin{tabular}{|c|c|c|c|}
\hline & Model 1 & Model 2 & Model 3 \\
\hline Gender & $.328 *$ & .198 & $.230^{+}$ \\
\hline Age & $.021 *$ & .010 & .012 \\
\hline $\mathrm{H}_{1}$ : Job dissatisfaction & & $-.476 * * *$ & $-.462 * * *$ \\
\hline $\mathrm{H}_{2}$ : Psychological capital & & $.252 * *$ & $.252 * *$ \\
\hline $\mathrm{H}_{3}$ : Job dissatisfaction $\times$ psychological capital & & & $.179 *$ \\
\hline $\begin{array}{r}\mathrm{R}^{2} \\
\mathrm{R}^{2} \text { change }\end{array}$ & .021 & $\begin{array}{c}.159 \\
138 * * *\end{array}$ & .169 \\
\hline
\end{tabular}

Notes: $\mathrm{N}=394$.

$* * * p<.001 ; * * p<.01 ; * p<.05 ;{ }^{+} p<.10$. 